\title{
Weight loss expectations and body dissatisfaction in young and older obese women attempting to lose weight
}

\author{
E. Evans ${ }^{1 *}$, J. Lara, E. Muscariello ${ }^{2}$, B. C. M. Stephan ${ }^{3}$, L. Petagna ${ }^{2}$, G. Nasti ${ }^{2}$, A. Colantuoni ${ }^{2}$ \\ and M. Siervo \\ ${ }^{1}$ Human Nutrition Research Centre, Institute for Ageing and Health, Newcastle University, Campus for Ageing and Vitality, \\ Newcastle on Tyne, NE4 5PL, UK. ${ }^{2}$ Human Nutrition and Physiology, Department of Neuroscience, University of Naples, \\ via Pansini 5, 80134, Naples, Italy, ${ }^{3}$ Institute for Health and Society, Newcastle University, Baddiley-Clark, Richardson \\ Road, Newcastle upon Tyne, NE2 4AX, UK
}

Unrealistic weight loss expectations (WLEs) have been linked to greater treatment attrition rates and worse long-term weight loss (WL) outcomes in young and middle-aged obese subjects. We aim to investigate 1) the link between WLEs and body image dissatisfaction in young and older obese women attempting to lose weight; 2) the relationship between WLEs, current body weight and recommended WL targets $(5 \%, 10 \%$ and $20 \%$ of baseline body weight).

Twenty-six young age (mean $=23.3$; $\mathrm{SD}=6.0$ years), with a mean body weight of 81.7 ( $\mathrm{SD}=9.3) \mathrm{kg}$, and mean $\mathrm{BMI}$ of 32.5 $(\mathrm{SD} 2.0) \mathrm{kg} / \mathrm{m}^{2}$; and thirty-three older age (Mean $=65.7, \mathrm{SD}=4.2$ years), with a mean body weight of 81.7 (SD 8.3) kg, and mean BMI of 35.0 (sD3.4) kg/m² obese women were recruited. Eating behaviour was assessed using the Eating Attitude Test-26 (EAT-26) ${ }^{(1)}$. The body dissatisfaction subscale of the Eating Disorder Inventory (EDI_BD) ${ }^{(2)}$ and the Body Image Assessment for Obesity ${ }^{(3)}$ were used to assess body image concern. WLEs were categorised according to personal, lifestyle and social factors.

The two groups were matched for body weight $(p>0.05)$. Older women identified a significantly larger current $(p<0.001)$ and ideal $(p<0.001)$ body size than younger women. Young women reported significantly greater levels of dieting $(p<0.001)$, bulimia $(p<0.001)$ and oral control $(p<0.001)$. The largest WLEs were perceived as coming from the mass media in young women, and the achievement of career success in older women. Young women with lower expected 'happy' $(p=0.003)$, 'reasonable' $(p=0.004)$ and 'fitness' $(p=0006)$ body weights had higher levels of bulimic symptoms, whilst older women did not.

The association between body size and WLEs in obese women was modified by age. The attitudinal constructs underlying these differences may be useful in clinical practice to improve WL outcomes.

1. Garner DM, Olmsted MP, Bohr Y, Garfinkel PE (1982) The eating attitudes test: psychometric features and clinical correlates. Psychol Med 12, 871878.

2. Garner DM, Olmstead M, Polivy J (1983) Development and validation of a multidimensional eating disorder inventory for anorexia nervosa and bulimia. Int J Eating Dis 2, 15-34.

3. Williamson DA, Womble LG, Zucker NL, Reas DL, White MA, Blouin DC et al. (2000) Body image assessment for obesity (BIA-O): development of a new procedure. Int J Obes Relat Metab Disord 24, 1326-1332. 